\title{
The Effect of Blended Learning in Covid-19 Pandemic with the Achievement of Internal Medicine Stage Competencies at the Clerkship Program of the Faculty of Medicine UII
}

\author{
Rina Juwita, Erlina Marfianti, Ana Fauziyati*, Barmawi Hisyam \\ Department of Internal Medicine, Faculty of Medicine Universitas Islam Indonesia, Yogyakarta \\ Corresponding author: Ana Fauziyati, email 047110434@ uii.ac.id
}

\begin{abstract}
Background

The Covid-19 pandemic had an impact on all aspects of life including medical education at the Faculty of Medicine Universitas Islam Indonesia. Clinical learning was modified into combination of online and offline learning or blended learning. This study aimed to see the learning outcomes of students at the Internal Medicine stage between those who underwent conventional learning i.e. 11 weeks full of offline education in the hospital and those who underwent blended learning, namely 4 weeks online followed by 7 weeks offline.

Method

This study was a case control study that aimed to compare the competency attainment of the Internal Medicine stage in a group of students who underwent blended learning versus those who underwent full offline learning. Competency achievement was seen from assessment scores (Mini-Clinical Evaluation Exercise (Mini-CEx), Direct Observation of Procedural Skills (DOPS), clinical tutorials, journal reading, case reflection, Objective Structured Long Examination Record (OSLER), written test scores and final scores. The statistical analysis used was descriptive analysis and the Mann Whitney sample test. The difference was significant if $\mathrm{p}<0.05$. This study had received ethical clearance from the Ethics Committee of FK UII.

Result

Initially we selected 30 students for each group, but data that met the inclusion criteria were obtained for 13 students who underwent blended learning and 18 students who had an offline stage. The data that were excluded were incomplete assessment data. The study was conducted in December 2020 - January 2021. There were significant differences in the case reflection scores, written examinations and final scores between the two groups with a p value $<0.05$ in sequence; $0.00,0.03$, and 0.001 . Meanwhile, the scores for Mini-CEx, DOPS, journal reading, clinical tutorial, and OSLER were not significantly different. The mean value obtained by the offline group was better than the blended learning group.

Conclusions

The competency achievement shown by the assessment results in the blended learning method group was lower than the offline method group for the medical professional education program during the Covid-19 pandemic.
\end{abstract}

Keywords: competence, blended learning, Covid-19 pandemic. 


\section{INTRODUCTION}

The Covid-19 pandemic is not over yet. Since one year ago, it had hit the whole world without exception, including Indonesia. This condition will have a broad impact in all areas of life, including medical education. Learning that was originally carried out face-to-face has turned into distance learning. On March 10, 2020 UNESCO held an emergency meeting for the closure of educational facilities with support for the implementation of large-scale distance learning programs to reach learners remotely [1]. This is reinforced by the 'Surat Edaran' (SE) issued by the government on March 18, 2020, all indoor and outdoor activities in all sectors are temporarily postponed to reduce the spread of Covid-19, especially in the education sector. On March 24, 2020 the Minister of Education and Culture of the Republic of Indonesia issued Letter Number 4 In 2020 concerning the Implementation of Education Policies in an Emergency for the Spread of Covid-19, the Letter explains that the learning process is carried out at home through online or distance learning [2]. Clinical medical education changed the learning method from the clinical rotation system which was originally carried out in the hospital by directly looking closely and participating in patient management under the guidance of the Doctor in Charge of Services for 11 weeks to Blended Learning, namely distance learning for 4 weeks continued face to face for 7 weeks. One of the right solutions in distance learning is using the blended learning system.

Blended learning is gaining popularity and is very widely used by many medical campuses using the internet and learning forums. Elearning requires learning equipment that is constantly updated, interactive learning, independent learning and easy access [3]. Blended learning is a combination of face-toface and online instruction, a combination of various different training media to create an optimal learning program [4].

Online learning is not without challenges. Many studies have cited the challenges of distance learning, including time management, use of technology, student assessment, communication and a lack of person-to-person interaction. The obstacle that is often encountered is the difficulty of students accessing devices such as computers or laptops or the stability of the internet where they live. Apart from the students, often from clinical educators there are also challenges, including technology illiteracy (technophobia) [5].

Changes in learning methods that have been used in the form of Evidence Based Medicine $(\mathrm{EBM})$, which in practice interact a lot with patients and cases that will be faced and are difficult to apply as a whole during a pandemic. The principles of EBM are to shape the pattern of decision making by integrating the best evidence-based clinical experience with the clinical opinion of the experts and the patient's condition. Adopting the EBM approach to medical education requires that actors be able to understand and apply the following in clinical practice:

(i) Asking for anamnesis using the PICO format (patient, intervention, comparison, outcome);

(ii) Finding evidence based on systematic and efficient literature searches;

(iii) Assessing findings through critical appraisal techniques;

(iv) Applying the evidence to clinical scenarios; and,

(v) Assessing the EBM process as it relates to the clinical context [6].

The application of pure EBM is difficult to apply when a pandemic strikes. It is necessary to innovate with the blended learning model, students who undergo clinical rotation can still achieve competence so that there are changes in learning methods using e-learning facilities or virtual cases that can be accessed anywhere and anytime. E-learning or distance learning methods in medical education may represent a suitable alternative for changing from traditional learning to high-quality education. Availability of critical infrastructure and efficient institutional strategies represent. Although this method has been well adopted in various countries, electronic distance learning tends to be unfamiliar, especially in developing countries [7]. It is the main challenge to integrate distance learning in medical education so that it can still fulfill its competence as a doctor. 
This study was aimed to determine the learning outcomes of students at the Internal Medicine stage between those who underwent a full 11 weeks of offline education in the hospital and those who underwent blended learning, namely 4 weeks online followed by 7 weeks offline.

\section{METHOD}

This study was a case control study comparing the achievement of competency in the Internal Medicine stage in a group of 13 students who underwent blended learning compared to 18 people who underwent full offline learning. Competency achievements were seen from the assessment scores (MiniCEx, DOPS, clinical tutorials, journal reading, case reflection, OSLER, written test scores and final grade scores) in Internal Medicine stage. The statistical analysis used was descriptive analysis and the Mann-Whitney test. The difference is significant if $\mathrm{p}<0.05$. This study had obtained ethical clearance from the FK UII Ethics Committee.

\section{RESULT AND DISCUSSION}

\subsection{Result}

\subsubsection{Normality test}

Based on the results of the assessment of 8 types of assessment during the student undergoing clinical rotation in internal medicine, a normality test was obtained which showed an abnormal distribution.

\subsubsection{Learning outcomes}

The average learning outcomes compared in this study are shown in table 1 below. The average student assessment results in both groups appeared to be higher in the group undergoing conventional clinical rotation. In the blended learning group, the lower average score is likely to be influenced by the adaptation of students to changing methods due to the pandemic.

Table 1. Mean Comparison

\begin{tabular}{|l|c|c|c|c|}
\hline \multicolumn{1}{|c|}{ ASSESMENT } & \multicolumn{2}{c|}{ CONVENTIONAL } & \multicolumn{2}{c|}{ BLENDED LEARNING } \\
\hline & Mean & SD & Mean & SD \\
\hline Mini Clinical Examination & 84.78 & 5.05 & 81.75 & 1.6 \\
\hline Clinical Tutorial & 95.42 & 4.13 & 94.61 & 8.78 \\
\hline Journal Reading & 90.61 & 2.99 & 95 & 6.45 \\
\hline DOPS & 85.57 & 3.09 & 83.67 & 3.67 \\
\hline Case Reflection & 97.06 & 4.62 & 83.08 & 4.35 \\
\hline Written Examination & 81.76 & 7.89 & 72.03 & 8.49 \\
\hline OSLER & 86.04 & 4.75 & 85.90 & 2.12 \\
\hline Final Score & 85.65 & 2.76 & 82.65 & 1.35 \\
\hline
\end{tabular}

\subsubsection{Comparison of Assessment Results}

The results of the comparison of learning outcomes are shown with eight assessments that must be completed by students undergoing clinical rotation in the teaching hospital. The assessments that used were Mini-CEx, DOPS, clinical tutorial, journal reading, case reflection, OSLER, written test scores and final grade scores. The results can be seen in Figure 1 below. 
Test Statistics ${ }^{a}$

\begin{tabular}{|c|c|c|c|c|c|c|c|c|}
\hline & Nilai miniCEx & $\begin{array}{l}\text { Nilai Tutorial } \\
\text { Klinik }\end{array}$ & Nilai DOPS & $\begin{array}{l}\text { Nilai Journal } \\
\text { Reading }\end{array}$ & $\begin{array}{l}\text { Nilai Refleksi } \\
\text { Kasus }\end{array}$ & $\begin{array}{l}\text { Nilai Ujian } \\
\text { Tulis Stase }\end{array}$ & Nilai OSLER & Nilai Akhir \\
\hline Mann-Whitney U & 82.500 & 97.500 & 74.000 & 69.500 & 7.000 & 44.000 & 93.000 & 37.000 \\
\hline Wilcoxon W & 173.500 & 268.500 & 165.000 & 240.500 & 98.000 & 135.000 & 184.000 & 128.000 \\
\hline Z & -1.382 & -.835 & -1.730 & -1.918 & -4.557 & -2.926 & -.961 & -3.203 \\
\hline Asymp. Sig. (2-tailed) & .167 & .404 & .084 & .055 & .000 & .003 & .337 & .001 \\
\hline $\begin{array}{l}\text { Exact Sig. [2*(1-tailed } \\
\text { Sig.)] }\end{array}$ & $.170^{\mathrm{b}}$ & $.441^{\mathrm{b}}$ & $.089^{\mathrm{b}}$ & $.056^{\mathrm{b}}$ & $.000^{\mathrm{b}}$ & $.003^{\mathrm{b}}$ & $.352^{\mathrm{b}}$ & $.001^{\mathrm{b}}$ \\
\hline
\end{tabular}

a. Grouping Variable: Kelas Konvensional/Luring atau Daring-Luring (Blended Learning)

b. Not corrected for ties.

Figure 1. Analysis of the results of the assessment method

From the picture above, it appears that the assessment results of these 2 groups of students show a significant difference in the case reflection scores $(0.00, \mathrm{p}<0.05)$, the written test $(0.003, \mathrm{p}<0.05)$ and the final score $(0.001, \mathrm{p}$ $<0.05)$. Meanwhile, the other assessment results showed insignificant differences. Looking at the results, assessments that test skills such as mini-CEx and DOPS are not significant. However, at the end of the stage assessment, the difference in the scores of the two groups using this method was significantly different and higher for the conventional group.

\subsection{DISCUSSION}

The results of this study can be seen that the mean learning outcomes of students who underwent clinical rotations in the conventional way in teaching hospitals were higher than those who underwent blended learning. Some problems and challenges faced at this moment. This is according with the results of the study by Hau et al., that studied students undergoing clinical rotations in surgery. Finding some things that are a challenge in gaining case handling experience skills. These things are shown in table 2 below [8]. The great impact of the pandemic on clinical medical education is very pronounced and there are enormous challenges that must be faced by both teachers and students. The number of cases handled is greatly reduced, the limitation of interaction with patients, the reduction in the number of specialist doctor personnel on duty, the reduction in non Covid-19 ward rooms because some wards are functioned as emergency isolation rooms for handling Covid-19, the delay in several assessments is due to the absence of cases that are in accordance with competence doctors [5,7].

Table 2. Problems and Challenges Problems and Challenges

1. Disruption to clinical rotation, especially training, limited skills/assistance of specialist doctors, inability to improve the ability to practice in hospitals, and lack of monitoring of the impact of learning.

2. Limited access to elective cases and the closure of several operating rooms.

3. Postponement of the advanced surgical technique training course.

4.Focus on exposure to covid 19

5. Lack of personal protective equipment (PPE)

6. Lack of inter-team communication, social distancing, and independent isolation.

7. There is no activity on campus

8. Interference with student training and education schedules

9. Requires motivation to learn independently

10. Mental health problems - anxiety, fear of catching/passing on

11. Requires time management skills 


\begin{tabular}{|l|}
\hline 12. More theory repetition than hands-on practice. \\
\hline 13. Availability of backup personnel \\
\hline
\end{tabular}

Some literature states that this year it is difficult to develop clinical skills, as well as the practical health examination or OSCE and many medical campuses have to cancel or postpone its implementation this year. The Covid-19 pandemic is accelerating the breakthrough of alternative education methods and study techniques that are able to adapt to conditions [9].

Assessment of student learning outcomes that are carried out when transitioning from the conventional method, namely students fully study at the Teaching Hospital compared to students who take blended learning, obtained different mean results which are significantly higher in the conventional group compared to blended learning, namely the results of case reflections, written exams and final exams. There are many things that can affect this assessment, among others, the variety of cases that are eligible to be used as cases that meet the criteria is limited, the exposure to the number of cases that should be met in the field is reduced, meetings with specialist doctors cannot be carried out optimally, and internet facilities are on-site. Students undergo clinical education which is sometimes less stable and makes it difficult for students to study optimally.

Pennel et al., explained that there must be accelerated methods of good clinical education. The team of Newcastle University clinical educators at John Hunter Hospital has developed the concept of 'live-streamed ward rounds'. This is intended to answer the challenge of maintaining the student clerkship education model set by the hospital in a few months for students who do not undergo clinical rotation. in hospital because of the pandemic. This live broadcast consists of three phases, which are described in Figure 2 below:

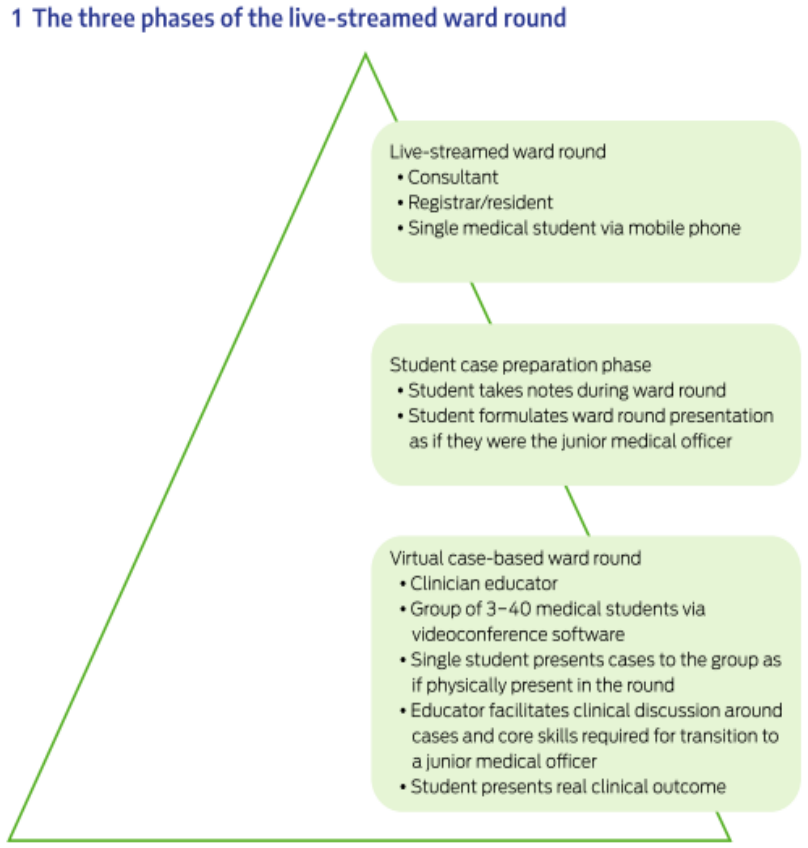

Figure 2. Three phases of live-streamed ward rounds 
This breakthrough is considered to have many benefits, including reduced intensity of direct contact with patients, various cases that can be presented, students become part of the clinical team, the opportunity to ask questions and receive useful information from patients, get high level supervision, and get bed site teaching. The process of visiting patients is time consuming and requires stable and reliable internet and streaming equipment [10]. Pandemic conditions encourage clinical educators to be more innovative and creative.

The advantages of this study are that it turns out that blended learning that had to be carried out as an adaptation to the Covid-19 pandemic did not reduce the medical abilities and skills of students as seen from the differences between the two groups which were not significantly different. So that it becomes an encouragement for clinical educators to be more enthusiastic and look for the best breakthroughs so that students can still become competent doctors in the midst of a pandemic atmosphere.

The weakness of this study is the small number of samples and is not accompanied by data such as place of education, cumulative grade point average, and complete demographic data. So it is necessary to do research with a larger sample and more completely data.

\section{CONCLUSION}

The results of the assessments of internal medicine stage learning outcomes for medical students using blended learning during COVID-19 pandemic had been decreased compared with the conventional program. The assessment results in three types of assessments were decreased but were not different in the ability of student's clinical skills. It is necessary to study and examine more creative efforts to improve the assessment results of students who have to take part in blended learning.

\section{AUTHORS CONTRIBUTIONS}

Rina Juwita was the Chief of Research Team who writing the full paper; Erlina Marfianti developed the research proposal and gained the ethical clearance, Ana Fauziyati searched and analyzed the data and then submitted to ICME as corresponding author, Barmawi Hisyam was the consultant of the research.

\section{ACKNOWLEDGMENT}

We thank to Faculty of Medicine Universitas Islam Indonesia for financial and official supports in conducting this study and submitting to ICME.

\section{REFERENCES}

[1] S. Handayani, Annisya, A. Wati., Peningkatan Kemandirian Belajar Mahasiswa di Masa Pandemi Covid-19 melalui Penerapan Blended learning pada Mata Kuliah Evaluasi Proses dan Hasil Belajar di Universitas Negeri Malang, Jurnal Pendidikan Ekonomi, 2020, Vol.13, No.2 DOI: https://dx.doi.org/10.17977/UM014v13i2 $\underline{2020 \mathrm{p} 152}$

[2] F. Budiono, Implementasi Blended Learning di Masa Pandemi, Prosiding Diskusi Daring Tematik Nasional, 2020, pp 9-12

[3] N. Makhdoom, K.I. Koshhal, S. Algaidi, K. Heissam, 'Blended learning' as an effective teaching and learning strategy in clinical medicine: a comparative crosssectional university-based study, Journal of Taibah University Medical Sciences, 2013, Vol. 8, pp. 12-17, DOI: https://doi.org/10.1016/j.jtumed.2013.01. $\underline{002}$

[4] C. Herbert, G.M. Velan, W.M. Pryor., R.K. Kumar, A model for the use of blended learning in large group teaching sessions, BMC Medical Education 2017, 17(1):197, pp. 1-11 DOI: https://doi.org/10.1186/s12909-0171057-2

[5] M.H. Rajab, A.M. Gazal, K. Alkattan, Challenges to Online Medical Education During the COVID-19 Pandemic, Cureus 2020, 12 (7), pp. 1-11 DOI: https://doi.org/10.7759/cureus.8966 
[6] D.Ilic, W. Hart, P. Fiddes, M. Misso, E. Villanueva, Adopting a blended learning approach to teaching evidence based medicine: a mixed methods study., $B M C$ Medical Education 2013, 13:169, pp. 1-11 DOI: https://doi.org/10.1186/1472-6920$\underline{13-169}$

[7] M. Al-Balas, H.I. Al-Balas, H.M. Jaber, K. Obeidat, H. Al-Balas, et.al., Distance learning in clinical medical education amid COVID-19 pandemic in Jordan: current situation, challenges, and perspectives, BMC Medical Education 2020, 20:341, pp. 1-7 DOI: https://doi.org/10.1186/s12909-02002257-4

[8] H.M. Hau, J. Weitz, U. Bork, Impact of the Covid-19 Pandemic on Student and Resident Teaching and Training in Surgical Oncology, J. Clin. Med. 2020, 9, 3431, pp. 1-15 DOI: https://doi.org/10.3390/jcm911343i

[9] A.M. Monaghan, Medical Teaching and Assessment in the Era of COVID-19, Journal of Medical Education and Curricular Development 2020, Volume 7, pp.1-3 DOI: https://doi.org/10.1177/23821205209652 55

[10] C.E. Pennell, H. Kluckow, S.Q. Chen, K.M. Wisely, B.L. Walker, Live-streamed ward rounds: a tool for clinical teaching during the COVID- 19 pandemic, MJA 2020, 213 (7) pp. 306-308 DOI: https://doi.org/10.5694/mja2.50765 